\title{
Development and validation of inexpensive, automated, dynamic flux chambers
}

\author{
B. B. Almand-Hunter ${ }^{1}$, J. T. Walker ${ }^{2}$, N. P. Masson ${ }^{1}$, L. Hafford ${ }^{1}$, and M. P. Hannigan ${ }^{1}$ \\ ${ }^{1}$ Mechanical Engineering Department, University of Colorado, 427 UCB, Boulder, CO, 80303, USA \\ ${ }^{2}$ Air Pollution Prevention and Control Division, National Risk Management Research Laboratory, US Environmental \\ Protection Agency, E305-2, MD-63, Research Triangle Park, NC 27711, USA
}

Correspondence to: B. B. Almand-Hunter (berkeley.almand@ colorado.edu)

Received: 15 May 2014 - Published in Atmos. Meas. Tech. Discuss.: 10 July 2014

Revised: 29 October 2014 - Accepted: 19 November 2014 - Published: 13 January 2015

\begin{abstract}
We developed and validated an automated, inexpensive, and continuous multiple-species gas-flux monitoring system that can provide data for a variety of relevant atmospheric pollutants, including $\mathrm{O}_{3}, \mathrm{CO}_{2}$, and $\mathrm{NO}_{\mathrm{x}}$. Validation consisted of conducting concurrent gas-phase drydeposition experiments, using both dynamic flux chambers and an eddy-covariance system, in a grassy clearing in the Duke Forest (Chapel Hill, NC). Experiments were carried out in June and September under a variety of meteorological conditions. Ozone-deposition measurements from the two methods matched very well (4-10\% difference in mean flux rate) when the leaf-area index (LAI) inside the chambers was representative of the average LAI in the field. The dynamic flux chambers can be considered an accurate measurement system under these conditions.
\end{abstract}

\section{Introduction}

Deposition of pollutants - including ozone, nitrogen, and acidic compounds $\left(\mathrm{SO}_{\mathrm{x}}, \mathrm{NO}_{\mathrm{y}}\right)-$ places environmental stress on sensitive vegetated landscapes and aquatic ecosystems (Driscoll et al., 2001; Williams and Tonnessen, 2000; Fangmeier et al., 1994). Examples of this stress include increased susceptibility to injury (DeHayes et al., 1999) and decreased growth for sensitive plant species, decreased water quality, toxicity to freshwater organisms, eutrophication, change in greenhouse emissions from soil (Fenn et al., 1998), reduction in biodiversity, and interference with a plant's uptake of other important cations, such as potassium (Fangmeier et al., 1994). These negative effects can be particu- larly pronounced at high altitudes, where buffering capacities can be below average (Fenn et al., 1998; Williams and Tonnessen, 2000; Benedict et al., 2013). There has been debate over whether ozone damage to vegetation is best quantified and regulated using ambient concentrations or atmospheric fluxes (Musselman et al., 2006). While the use of ambient concentrations is certainly much simpler, fluxes have more physical meaning.

Dry deposition, which is the process by which pollutants are transported from the atmosphere to the earth's surface without precipitation (Seinfeld and Pandis, 2006), is an important component of atmospheric deposition. This process is estimated to account for up to $50 \%$ of total atmospheric deposition in the United States (EPA, 2010; Wesely and Hicks, 2000). Despite this sizable contribution to total atmospheric deposition, there is a shortage of direct measurements of dry deposition in the US. Because of this measurement shortage, improving deposition models is crucial. Additionally, understanding deposition and emission rates is an important piece of estimating atmospheric concentrations in the planetary boundary layer for climate and weather models. Efforts to improve deposition models are ongoing (Saylor et al., 2014; Zhang et al., 2003; Brook et al., 1999; Pleim et al., 2013), and models estimate flux well under some conditions, but fluxes determined by different models and observations can vary by a factor of 2 to 3 (Schwede et al., 2011; Wu et al., 2011; Flechard et al., 2011). Direct dry-deposition measurements are needed to improve and validate models for a variety of ecosystems and environmental conditions.

The main reason for the shortage of direct dry-deposition measurements is that the current measurement methods are 
prohibitively expensive and complex. This results in significant uncertainty in deposition loads, specifically regarding transfer ratios (the relationship between ambient concentrations and total deposition). Given the large spatiotemporal variability in air-surface exchange rates of reactive compounds, there is a need for low-cost, easily deployable systems to measure dry deposition directly. These measurement devices should be automated and remotely controlled, so that they can be deployed for extended periods of time without excessive maintenance.

Currently, the most accurate direct method for measuring atmospheric fluxes is eddy covariance (Seinfeld and Pandis, 2006; Turnipseed et al., 2009). Eddy covariance consists of taking high-speed measurements of concentration and three-dimensional wind velocity. The flux is computed from the covariance between the fluctuating components of wind velocity and concentration (Turnipseed et al., 2009). This method is the most mathematically robust and accurate way to acquire dry-deposition measurements, but it is expensive and technically difficult compared with indirect measurement methods (Baldocchi et al., 1988).

Another method for measuring flux, which is used more frequently to measure emissions than it is to measure deposition, is the flux chamber. Advantages of flux chambers over eddy covariance include reduced cost, the ability to determine spatial variability in deposition, the ability to take measurements in areas with complex topography and areas with non-uniform vegetation (eddy covariance typically requires an area of uniform vegetation that is $\geq 100 \mathrm{~m}^{2}$ ), mobility, and the potential to be used with inexpensive sensors (Horst and Weil, 1994). The main drawback of using chambers for flux measurements is that they alter the environment in which they are placed. Static chambers, which are commonly used to measure emissions, significantly affect environmental conditions (Pape et al., 2009).

Dynamic flux chambers minimize the alteration of environmental conditions by constantly pumping ambient air into the chamber. Table 1 lists previous flux-chamber measurements of $\mathrm{NO}, \mathrm{NO}_{2}, \mathrm{CO}_{2}$, and $\mathrm{O}_{3}$. One type of flux chamber listed in Table 1 is the leaf-scale dynamic chamber, which is used to measure fluxes to and from individual leaves and branches (Breuninger et al., 2012, 2013; Geßler et al., 2000; Sparks et al., 2001; Altimir et al., 2002). While leaf-scale deposition measurements are important for understanding plant dynamics, they can be difficult to translate to the canopy scale and do not directly represent ecosystem-level flux.

Another type of chamber listed in Table 1 is the dynamic soil-flux chamber (Remde et al., 1993; Norman et al., 1997). A significant portion of the chambers listed did not have open tops, and the soil or vegetation in the chamber was only exposed to ambient conditions via air pumped into the chamber. These chambers, which are not normally open to the ambient environment, have significant drawbacks. They all block a fraction of incoming solar radiation, and in order to main- tain ambient conditions they have to be moved frequently, which makes long-term or remote deployments difficult.

Several research groups have addressed these issues by developing chambers with lids that open and close automatically (Meixner et al., 1997; Pape et al., 2009; Kitzler et al., 2006). These automatic chambers operate in a normally open mode, with lids that close for just a few minutes per hour. Provided that the chambers are made out of highly transparent materials, so sunlight can reach the vegetation inside, the environmental conditions in the chamber remain very close to ambient (Pape et al., 2009).

While many chamber measurements have been made (Table 1), very few of these studies compare $\mathrm{O}_{3}$ fluxes measured by chambers to measurements acquired via micrometeorological techniques. Several groups have compared chamber measurements of NO fluxes from soils to gradient measurements (Parrish et al., 1987; Stella et al., 2012). Norman et al. (1997) compared several types of static and dynamic chambers with each other and eddy correlation for measuring $\mathrm{CO}_{2}$ fluxes in forest soils, but only two data points for eddy correlation were available for comparison, each representing one day. Li et al. (1999) compared chamber measurements of NO fluxes from agricultural soils with eddy-correlation measurements and found that the fluxes measured by the chambers were higher than the eddy-correlation measurements but followed a similar diurnal trend. Pape et al. (2009) compared an automatic, dynamic flux chamber with an eddy-covariance system at a grassland site and demonstrated good agreement for $\mathrm{CO}_{2}$ deposition. Due to the fact that these comparison studies are limited in number, and sometimes did not yield good agreement between methods, further comparisons of flux chambers and micrometeorological methods are warranted.

Our research effort expands on this validation-based fluxchamber development through the creation of an automated, inexpensive, and continuous multiple-species gas-flux monitoring system, which can provide data for a variety of relevant atmospheric pollutants, including $\mathrm{O}_{3}, \mathrm{CO}_{2}$, and $\mathrm{NO}_{\mathrm{x}}$. The chambers have automatic lids, which keep the environment in the chambers close to ambient, and eliminate the need to regularly remove them from sampling plots. This project is unique because our chambers not only build on the limited chamber-validation literature, but also utilize an inexpensive design ( $<$ USD 2000 each). The chambers are equipped with inexpensive metal-oxide $\mathrm{O}_{3}$ and $\mathrm{NO}_{2}$ sensors, which cost between USD 10 and 100, and our ultimate goal is to obtain fluxes using these inexpensive sensors. The first step toward reaching that goal is to use data from established $\mathrm{O}_{3}, \mathrm{CO}_{2}$, and $\mathrm{NO}_{\mathrm{x}}$ monitors to validate the dynamic flux-chamber measurements, which enables us to isolate the uncertainty related to the use of inexpensive sensors from chamber performance. We present preliminary results, comparing chamber fluxes to eddy-covariance fluxes for $\mathrm{O}_{3}$ and $\mathrm{CO}_{2}$, and present $\mathrm{NO}_{\mathrm{x}}$ fluxes measured by the flux chamber. 
Table 1. Summary of selected chamber measurements of $\mathrm{NO}_{2}, \mathrm{NO}, \mathrm{O}_{3}$, and $\mathrm{CO}_{2}$.

\begin{tabular}{|c|c|c|c|c|}
\hline Reference & Gases measured & Surface & Chamber type & Validation method \\
\hline Altimir et al. (2002) & $\mathrm{CO}_{2}, \mathrm{O}_{3}$ & Scots pine shoots & dynamic, shoot chamber & compared w/typical $\mathrm{O}_{3}$ flux values \\
\hline Breuninger et al. (2012) & $\mathrm{NO}_{2}, \mathrm{NO}, \mathrm{CO}_{2}, \mathrm{O}_{3}$ & Norway spruce & dynamic, branch chamber & none \\
\hline Breuninger et al. (2013) & $\mathrm{NO}_{2}, \mathrm{NO}, \mathrm{CO}_{2}, \mathrm{O}_{3}$ & Norway spruce & dynamic, branch chamber & none \\
\hline Gut et al. (2002) & $\mathrm{NO}_{2}, \mathrm{NO}, \mathrm{CO}_{2}, \mathrm{O}_{3}$ & soil & dynamic & model comparison (using ambient concentration) \\
\hline Horváth et al. (2006) & $\mathrm{NO}, \mathrm{O}_{3}$ & spruce and oak soil & dynamic & none \\
\hline Kirkman et al. (2002) & $\mathrm{NO}_{2}, \mathrm{NO}, \mathrm{O}_{3}$ & pasture & dynamic & none \\
\hline Li et al. (1999) & $\mathrm{NO}$ & agricultural soil & dynamic & $\begin{array}{l}\text { chamber values larger than eddy covariance, but var- } \\
\text { ied similarly with time }\end{array}$ \\
\hline Meixner et al. (1997) & $\mathrm{NO}, \mathrm{NO}_{2}, \mathrm{O}_{3}$ & grassland and crops & dynamic, automated lid & none \\
\hline Norman et al. (1997) & $\mathrm{CO}_{2}$ & forest soil & dynamic and static & $\begin{array}{l}\text { compared } 5 \text { types of chambers and } 2 \text { eddy-covariance } \\
\text { data points }\end{array}$ \\
\hline Pape et al. (2009) & $\mathrm{NO}_{2}, \mathrm{NO}, \mathrm{CO}_{2}, \mathrm{O}_{3}$ & grassland & dynamic, automatic lid & $\begin{array}{l}\text { very good agreement w/eddy covariance for } \mathrm{CO}_{2}(\mathrm{did} \\
\left.\text { not compare } \mathrm{NO}, \mathrm{NO}_{2} \text {, and } \mathrm{O}_{3}\right)\end{array}$ \\
\hline Parrish et al. (1987) & NO & grassland & dynamic & nighttime comparison with gradient method \\
\hline Pilegaard (2001) & $\mathrm{NO}, \mathrm{NO}_{2}, \mathrm{O}_{3}$ & forest soil & dynamic, automated lid & none \\
\hline Remde et al. (1993) & $\mathrm{NO}, \mathrm{NO}_{2}, \mathrm{O}_{3}$ & marsh soil & dynamic & none \\
\hline Stella et al. (2012) & $\mathrm{NO}$ & agricultural soil & dynamic, automated lid & $\begin{array}{l}\text { agreed with gradient method for low fluxes, but under- } \\
\text { estimated high fluxes }\end{array}$ \\
\hline Unsworth et al. (1984) & $\mathrm{O}_{3}$ & soybeans & dynamic, open top & canopy resistances comparable to other field studies \\
\hline Williams and Davidson (1993) & NO & grassland & dynamic & comparison of 2 chamber types \\
\hline This study & $\mathrm{O}_{3}$ & grassland & dynamic, automatic lid & comparison with eddy covariance \\
\hline
\end{tabular}

\section{Methods}

\subsection{Overview}

We conducted gas-phase dry-deposition experiments in a grassy clearing in the Blackwood Division of Duke Forest in Orange County, North Carolina, USA $\left(35.97^{\circ} \mathrm{N}\right.$, $79.09^{\circ} \mathrm{W}$ ). The field is $480 \mathrm{~m} \times 305 \mathrm{~m}$, and the vegetation is primarily tall fescue (Festuca arundinacea Shreb.), which is a common C3 grass in the southeastern United States. Lessprominent vegetation includes $\mathrm{C} 3$ and $\mathrm{C} 4$ grasses, herbs, and forbs, which are present in smaller amounts (Fluxnet, 2013).

We used five pairs of acrylic-glass flux chambers to measure dry deposition of $\mathrm{NO}_{\mathrm{x}}, \mathrm{O}_{3}$, and $\mathrm{CO}_{2}$ to the grassland vegetation. Experiments were carried out in June and September, under a variety of meteorological conditions. We compared the chamber results with eddy-covariance measurements, which were conducted by the EPA at the same site.

\subsection{Leaf-area index}

The LAI in the field, as well as in chambers A and B, was measured on 11 November. LAI measurements in the open field were made by sampling at regular distances along $100 \mathrm{~m}$ transects ( $n=10$ locations) to the southwest and northwest of the eddy-covariance tower (prevailing fetch) with a LICOR Model LAI-2000 plant canopy analyzer (LI-COR Biosciences, Lincoln, NE). LAI measurements within the chambers were made by inserting the leaf area meter through a port at the bottom of the chamber. Individual measurements consisted of one above-canopy measurement and five belowcanopy measurements. Three replicate measurements were taken in each chamber. Measurements within the control chambers showed no difference between above- and belowcanopy measurements.

The LAI in the field was between 2.8 and 3.5, the LAI in chamber A was between 2.4 and 2.9, and the LAI in chamber B was between 2.75 and 3.1. While the chamber-LAI measurements were on the low end of the field measurements, they were inside the range of LAI measurements in the field. The mean grass height in the field did not significantly change between June and November, and measured heights were 42.2 and $43.7 \mathrm{~cm}$, respectively.

\subsection{Eddy-covariance measurements}

Above-canopy fluxes of $\mathrm{CO}_{2}, \mathrm{H}_{2} \mathrm{O}, \mathrm{O}_{3}$, sensible heat, and momentum were measured using an instrument package that consisted of an R.M. Young sonic anemometer (Model 81000 V, Traverse City, MI), aspirated thermocouple (Model ASPTC, Campbell Scientific, Logan, UT), LI-COR (Lincoln, NE) Model $7500\left(\mathrm{CO}_{2}\right.$ and $\left.\mathrm{H}_{2} \mathrm{O}\right)$ open-path infrared gas analyzer (IRGA), and a custom fast chemiluminescence $\mathrm{O}_{3}$ sensor, positioned at $2.5 \mathrm{~m}$ above the canopy. Gas-phase instruments were calibrated weekly by mass-flow-controlled dilution of compressed gas standards with clean air. Wind speed components $(u, v, w)$, temperature, and air concentrations were sampled at a frequency of $10 \mathrm{~Hz}$, and data were recorded on a single laptop, using a custom data-acquisition system. Data were reduced to $30 \mathrm{~min}$ and hourly averages using a custom SAS program (SAS Institute, 2003).

Eddy-covariance $\mathrm{O}_{3}$ fluxes were measured with a custom sensor that follows the basic design of Guesten et al. (1992), which consists of a pump (Model BTC IIS miniature diaphragm pump, Parker, Hollis, $\mathrm{NH}$ ), a reaction cell, and a photomultiplier tube (Model H9306 side-on photosensor, Hamamatsu, Middlesex, NJ) (Guesten et al., 1992). While 
Guesten et al. (1992) are generally credited with developing the first of these systems for flux measurement applications, a number of variants of the original design have been developed over the following years (see Zahn et al., 2012). This measurement technique is known as "dry chemiluminescence", and the air sample passes over a disk, which is coated with Coumarin-1 dye (Bagus Consulting, Speyer, Germany). The reaction of $\mathrm{O}_{3}$ with the dye results in luminescence, which is quantified by counting the resulting photons with a photomultiplier tube that views the reaction chamber from the side opposite the Coumarin disk. The ozone concentration is proportional to the number of photons produced. However, this is not an absolute measurement, and the disks have a limited lifetime over which the photon yield per unit $\mathrm{O}_{3}$ decreases. Thus, to calculate the absolute flux, the fast sensor must be calibrated to a second collocated sensor. The second sensor measures absolute $\mathrm{O}_{3}$ concentrations, at a frequency consistent with the timescale of the flux, which is $30 \mathrm{~min}$ to $1 \mathrm{~h}$. The collocated instrument is a Model 205 dual-beam instrument (2B Technologies, Boulder, $\mathrm{CO}$ ), which measures $\mathrm{O}_{3}$ by UV absorption. Ozone fluxes were calculated from $10 \mathrm{~Hz}$ measurements, calibrated to the $2 \mathrm{~B}$ sensor, using the ratio-offset method recommended by Muller et al. (2010).

For flux calculations, $10 \mathrm{~Hz}$ data were subjected to spike filtering, 2-D coordinate rotation, correction for the time delay between the chemical sensor and vertical velocity, application of Webb-Pearman-Leuning correction $\left(\mathrm{CO}_{2}, \mathrm{H}_{2} \mathrm{O}\right)$, and correction for high-frequency spectral attenuation $\left(\mathrm{O}_{3}\right)$ (Horst, 1997; Webb et al., 1980). The fast $\mathrm{O}_{3}$ sensor has an effective time response of approximately $1.5 \mathrm{~Hz}$. At lower frequencies, the cospectra of $\mathrm{O}_{3}$ and vertical velocity match the shape of the temperature/vertical velocity cospectra well, with both following the generalized cospectral characteristics described by Kaimal and Finnigan (1994). In this case, the method described by Horst (1997) was used to correct for spectral attenuation at frequencies $>1.5 \mathrm{~Hz}$ (Horst and Weil, 1994). Tests for stationarity and the presence of fully developed turbulence were also applied (Foken and Wichura, 1996). More information about the eddy-covariance method is available in the Supplement.

\subsection{Ancillary measurements}

Ancillary measurements included net solar radiation (Rebs Q7.1 Net Radiometer, Campbell Scientific, Logan, UT), photosynthetically active radiation (Model LI190 quantum sensor, LI-COR, Inc., Lincoln, NE), soil heat flux (Model HP101 heat flux plate, Hukseflux USA, Inc., Manorville, NY), soil temperature (thermocouple, OMEGA Engineering, Stamford, CT), soil volumetric water (Model CS615 water content reflectometer, Campbell Scientific, Logan UT) leaf wetness (Model 237, Campbell Scientific, Logan UT), and rainfall (Model TE525 rain gauge, Campbell Scientific, Logan, UT). Data are recorded on a Campbell Scientific CR23X datalogger and reduced to $30 \mathrm{~min}$ and hourly averages.

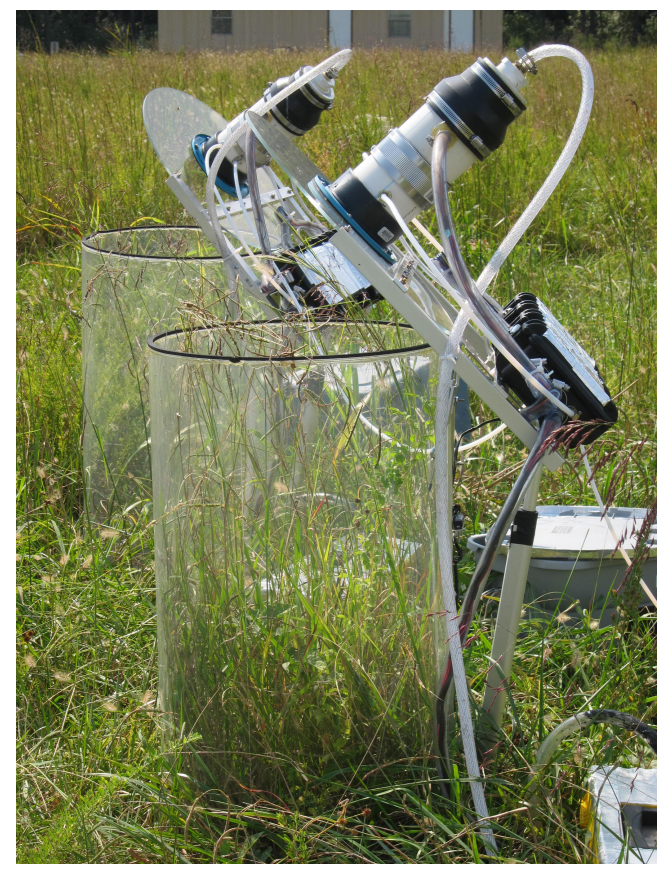

Figure 1. The photo above shows a pair of flux chambers at the field site in the Duke Forest.

\subsection{Flux-chamber description}

The dynamic flux chambers, which are shown in Fig. 1, were constructed using clear, cylindrically shaped acrylic. The chambers were constructed in pairs, and each pair had an open-bottomed chamber, which measured deposition to the vegetation inside, and a "blank" chamber, which had an acrylic bottom, and enabled us to measure deposition in the absence of vegetation. The blank measurement represents trace-gas losses to the chamber walls as well as any chemical reactions in the chamber that are unaccounted for in the flux calculations.

All of the chambers have a $45.7 \mathrm{~cm}$ diameter and $0.48 \mathrm{~cm}$ wall thickness. Four pairs of chambers have a height of $83.8 \mathrm{~cm}$, and the remaining pair has a height of $58.4 \mathrm{~cm}$. The chambers were designed with this height distribution because many species of natural vegetation, including grassland, are taller than $58.4 \mathrm{~cm}$. The shorter chambers were designed to measure fluxes over shorter vegetation, such as alpine tundra, which is present in sensitive areas like Rocky Mountain National Park. The shorter chambers are likely more accurate for vegetation below $59 \mathrm{~cm}$ tall, since they increase the ratio of vegetative surface area to volume.

The chambers were designed to minimize deposition of trace gases to the chamber walls, which was accomplished by placing the inlet and outlet holes in locations that limited contact between the flow path and the chamber walls. Ambient air enters the chambers through four holes, which are each $5.2 \mathrm{~cm}$ in diameter, and evenly spaced around the circumference of the chamber. The chamber outlet is at the 

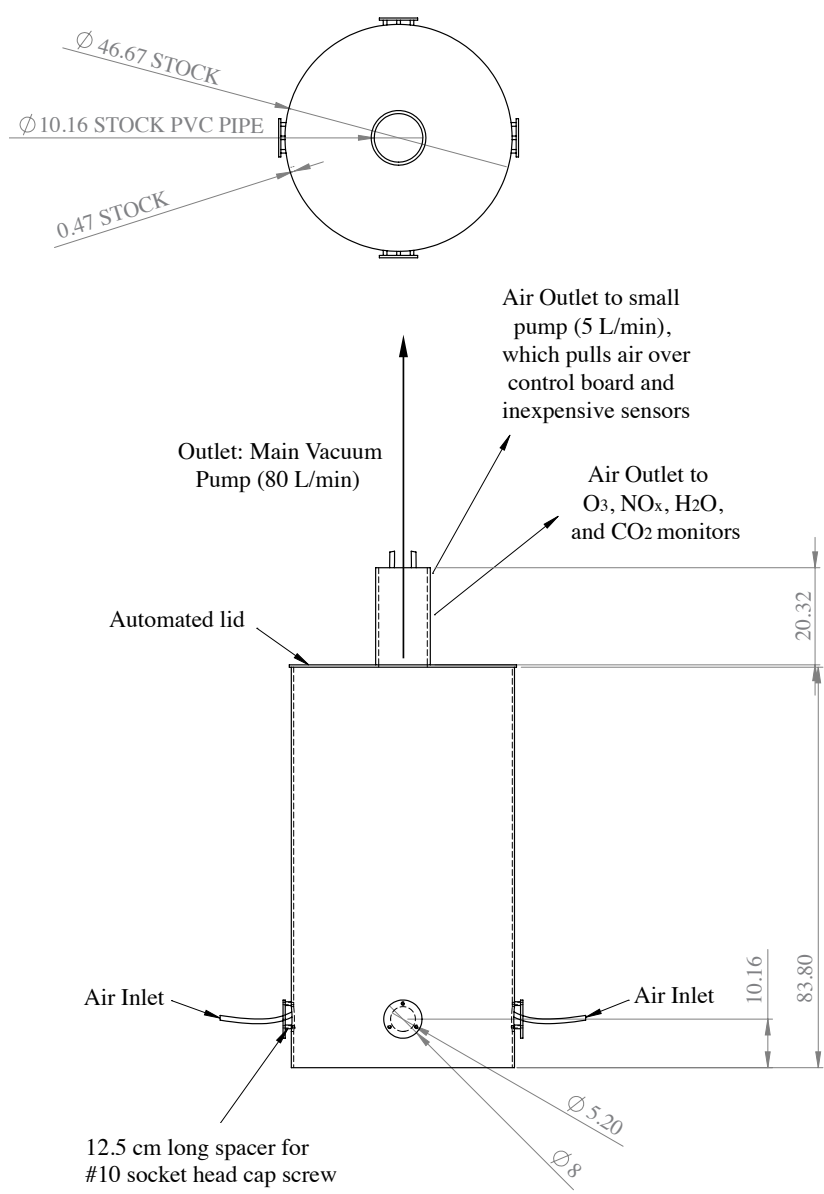

Figure 2. The plot above shows the dimensions of the chamber and the locations of the air inlets and outlet.

top of the chamber, as shown in Fig. 2. The grass outside the chamber, near the inlet holes, is removed, which prevents trace gases from depositing to external vegetation before the air stream enters the chamber.

Air is pulled through the chamber by a US General 3 CFM Two-Stage Vacuum Pump, and concentration samples were measured in one of two polytetrafluoroethylene (PTFE) tubes at the outlet. Gas-phase sampling is discussed in more detail in Sect. 2.6.

For most experiments, the pump was set to pull $80 \mathrm{~L} \mathrm{~min}^{-1}$ of air through the chamber. In addition to the flow induced by the vacuum pump, the $2 \mathrm{~B}$ ozone monitor pulled approximately $1 \mathrm{~L} \mathrm{~min}^{-1}$; the Thermo Scientific $\mathrm{NO}_{\mathrm{x}}$ analyzer pulled $0.1 \mathrm{Lmin}^{-1}$; the LI-COR $\mathrm{H}_{2} \mathrm{O} / \mathrm{CO}_{2}$ monitor pulled $0.25 \mathrm{~L} \mathrm{~min}^{-1}$; and the small, inexpensive pump, which pulled air over the inexpensive sensors, pulled $5 \mathrm{~L} \mathrm{~min}^{-1}$. Thus, the total flow rate through the chamber was $86.35 \mathrm{~L} \mathrm{~min}^{-1}$, which equates to a residence time of $1.5 \mathrm{~min}$. Pape et al. (2009) found that other researchers have operated dynamic flux chambers with residence times ranging from $10 \mathrm{~s}$ to 24 min and chose to operate their dynamic flux chambers at a residence time of $40 \mathrm{~s}$ (Pape et al., 2009). Gillis and Miller
(2000) found that changes in air-stream residence time in flux chambers caused proportional changes in mercury flux for both absorption and emission (Gillis and Miller, 2000). Aeschlimann and coworkers used a residence time of $15 \mathrm{~s}$ during the day and $60 \mathrm{~s}$ at night (Aeschlimann et al., 2005), which reflects ambient diurnal variation in friction velocity. Low residence times ensure that chambers are well mixed and minimize reactions between gases in the chamber. However, reducing residence times also reduces the difference in ambient and steady-state trace-gas concentrations in the chamber. Thus, as residence time is decreased, more precise instrumentation is required. We chose to operate our chambers with a $1.5 \mathrm{~min}$ residence time, because $1.5 \mathrm{~min}$ is sufficiently low to keep environmental conditions close to ambient yet still yield a trace-gas concentration change that is large enough to be detected by inexpensive sensors. This residence time also translates to a flow rate that can be generated with an inexpensive pump.

Another way that we reduced the cost of the chamber was by designing our own control system, using inexpensive electronic components. A customized embedded-system platform was used to automate the flux-chamber sampling system. The system is based on the low-cost M-Pod air quality monitor (Masson, 2014), with additional instrumentation for pump and actuator control. Firmware running on the common Atmel (San Jose, CA) Atmega 328 microcontroller controls both the data logging and flux-chamber sampling routine.

Each chamber runs approximately once an hour, and the main vacuum pump is off when the chamber is not sampling. Once per hour, a predefined and automated sampling schedule begins, and the vacuum pump turns on and runs with the lid open for $6.75 \mathrm{~min}$. The pressure change caused by the pump can cause fluctuations in instrument readings, and this boot-up time allows the instruments to stabilize before the chamber lid closes. After the $6.75 \mathrm{~min}$ initialization, the chamber lid closes and remains closed for $5 \mathrm{~min}$. It is important to note that the eddy-covariance measurements are fluxes averaged over a $30 \mathrm{~min}$ or $1 \mathrm{~h}$ time period, and the chamber measurements are a $5 \mathrm{~min}$ average, taken every $53 \mathrm{~min}$.

Fluxes were calculated based on the assumption that the chamber was well mixed. A mass balance in the chamber yields the equation

$V \frac{\mathrm{d} \mu_{j}(t)}{\mathrm{d} t}=Q \mu_{j, \mathrm{amb}}-Q \mu_{j}(t)-F_{j} A_{\mathrm{s}}$,

where $\mu_{j}(t)$ is the mixing ratio in the chamber of gas, $j$, with respect to time; $Q$ is the flow rate of air through the chamber; $\mu_{j, \text { amb }}$ is the ambient mixing ratio of gas, $j ; t$ is time; $A_{\mathrm{s}}$ is the surface area of the opening at the bottom of the chamber; $V$ is volume of the chamber; and $F_{j}$ is the flux of gas, $j$, to the vegetation. Differentiating, $\mu_{j}(t)$ is found to be 
Table 2. Trace gas detectors used in this study, with manufacturers' specifications.

\begin{tabular}{llllc}
\hline Time period & Detection method & Manufacturer and model & Detection limit & Precision \\
\hline $\mathrm{O}_{3}$ & UV light absorption & 2b Technologies (Boulder, CO) 202 & $1.5 \mathrm{ppb}$ & $\pm 1.5 \mathrm{ppb}$ \\
$\mathrm{NO}_{\mathrm{x}}$ & chemiluminescence & Thermo Scientific (Waltham, MA) 42S & $0.4 \mathrm{ppb}$ & $\pm 0.4 \mathrm{ppb}$ \\
$\mathrm{CO}_{2}$ & non-dispersive infrared gas analyzer & LI-COR (Lincoln, NE) 7000 & $0 \mathrm{ppm}$ & $0.01 \mathrm{ppm}$ \\
$\mathrm{H}_{2} \mathrm{O}$ & non-dispersive infrared gas analyzer & LI-COR (Lincoln, NE) 7000 & $0 \mathrm{ppm}$ & $0.01 \mathrm{ppm}$ \\
\hline
\end{tabular}

$\mu_{j}(t)=\mu_{j, \mathrm{amb}}-\frac{F_{j} A_{\mathrm{s}}}{Q}\left(1-e^{-\frac{Q}{V} t}\right)$.

The steady-state solution to this equation, solving for flux, is

$F=\frac{Q}{A_{\mathrm{s}}}\left(\mu_{j, \mathrm{amb}}-\mu_{j}\left(\tau_{\mathrm{ss}}\right)\right)$,

where $\tau_{\mathrm{ss}}$ is the time when the trace-gas concentration in the chamber reaches steady state.

\subsection{Gas-phase measurements}

Figure 2 shows the flow path of sample air through the chamber. Gas-phase measurements were conducted at the chamber outlet, which consisted of an $11.4 \mathrm{~cm}$ diameter PVC pipe. Chamber air was pulled through the outlet via the main vacuum pump. Two $4.76 \mathrm{~mm}$ diameter tubes were attached to the sides of the PVC pipe on one end, and instruments on the other. One tube was connected to a 2B Technologies Model 202 Ozone Monitor, Thermo Scientific Model 42S $\mathrm{NO}_{\mathrm{x}}$ analyzer, and LI-COR $7000 \mathrm{H}_{2} \mathrm{O} / \mathrm{CO}_{2}$ monitor. More information about the instruments is available in Table 2.

The second tube was connected to a small vacuum pump, which moved air through the chamber control box. In addition to the control board, the box housed metal-oxide $\mathrm{NO}_{\mathrm{x}}$ and $\mathrm{O}_{3}$ sensors. Additional data were collected using these commercially available sensors, specifically the Sensortech (Chemlsford, UK) (formerly e2v) MICS-2611 O 3 sensor. All low-cost sensors implemented in the flux-chamber system ranged in cost from USD 10 to 100 , and the $\mathrm{O}_{3}$ sensors had a detection limit well within typical concentration changes seen in ground-flux measurements. Complex quantification schemes are necessary to quantify the sensor output properly. Such schemes incorporate correction parameters for interference effects. Inexpensive sensor technology has the potential to be incorporated into a flux-chamber system effectively, which would make widespread flux measurements a realizable objective.

\subsection{Comparison of eddy-covariance and flux-chamber measurements}

Theoretically, dry deposition flux $(F)$ is proportional to the ambient concentration $(C)$ of a trace gas at some reference height (Seinfeld and Pandis, 2006). The proportionality constant between the concentration and flux is called "deposition velocity" $\left(v_{\mathrm{d}}\right)$ (Chamberlain and Chadwick, 1953), and

$F=-v_{\mathrm{d}} C$.

The deposition process has been described using a resistance analogy (Wesely and Hicks, 2000), in which species transport from the atmosphere to the surface of a material is controlled by three resistances in series.

$v_{\mathrm{d}}=\frac{1}{r_{\mathrm{t}}}=\frac{1}{r_{\mathrm{a}}+r_{\mathrm{b}}+r_{\mathrm{c}}}$,

where $r_{\mathrm{t}}$ is the total resistance to deposition, $r_{\mathrm{a}}$ is the resistance to aerodynamic transport, $r_{\mathrm{b}}$ is the resistance to diffusion through the quasi-laminar boundary layer, and $r_{\mathrm{c}}$ is the resistance to uptake of a trace gas by the canopy.

This resistance analogy is based on the assumption that the atmosphere is unaltered. It is an accurate analogy for eddycovariance measurements, but flux chambers alter the wind speed above the canopy, so the resistance analogy must be adjusted. Pape et al. (2009) proposed an alternate resistance scheme, which replaces $r_{\mathrm{a}}$ with $r_{\text {purge }}$ and $r_{\text {mix }}$, which represent the purging resistance between ambient and chamber air, and mixing in the chamber, respectively. When the chamber is well mixed, $r_{\text {mix }}$ is very small, and it can therefore be neglected in this case. $r_{\mathrm{b}}$ is replaced with a modified boundarylayer resistance, $r_{\mathrm{b}}^{*} \cdot r_{\mathrm{c}}$ should be modified very little by the chamber, provided the chamber does not substantially alter the environmental conditions (temperature, relative humidity) of the natural environment.

Thus, the ratio of chamber flux to ambient flux can be written as

$\frac{F_{\text {cham }}}{F_{\text {amb }}}=\frac{r_{\mathrm{a}}+r_{\mathrm{b}}+r_{\mathrm{c}}}{r_{\text {purge }}+r_{\mathrm{b}}^{*}+r_{\mathrm{c}}}$.

In order to find $r_{\text {purge }}+r_{\mathrm{b}}^{*}$, we conducted an experiment, placing a $15 \mathrm{~cm}$ dish of saturated potassium iodide solution (KI) in the bottom of a chamber that was filled with grass in the same height range as the field study. KI is an ideal ozone 


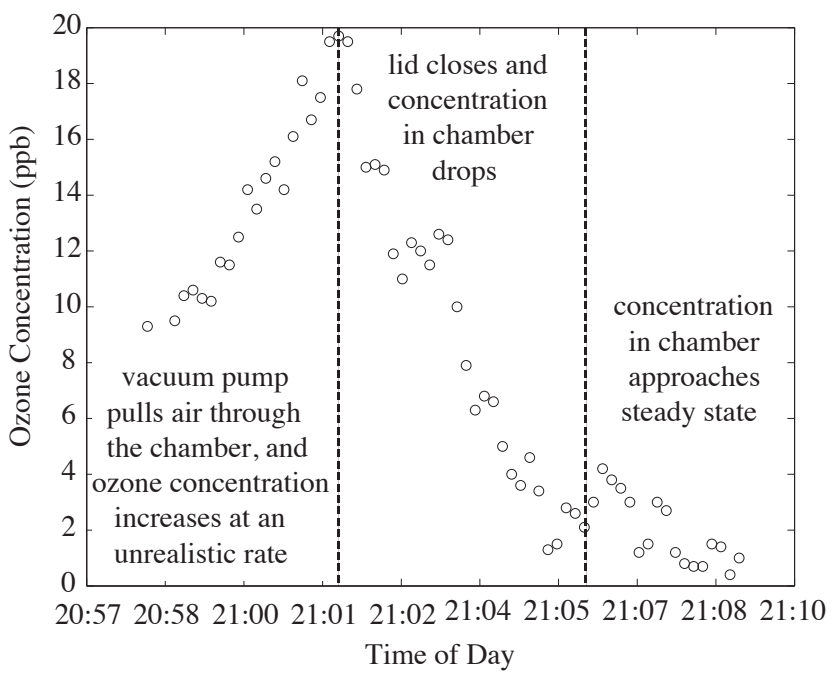

Figure 3. The plot above is an example of a run where the data could not be used to calculate a flux. The ozone concentration increases by an unreasonable amount when the chamber lid opens, which likely indicated malfunction in the $2 \mathrm{~B}$ ozone monitor.

sink, so $r_{\mathrm{c}}$ can be approximated as zero (Galbally and Roy, $1980)$ in this experiment. We used the equation

$v_{\mathrm{d}}=\frac{1}{r_{\text {purge }}+r_{\mathrm{b}}^{*}+r_{\mathrm{c}}}$

and the measured deposition velocity from the KI experiment to calculate $r_{\text {purge }}+r_{\mathrm{b}}^{*}\left(r_{\text {purge }}+r_{\mathrm{b}}^{*}=1 / v_{\mathrm{d}}=57.5 \mathrm{~s} \mathrm{~m}^{-1}\right)$. The value of $r_{\text {purge }}+r_{\mathrm{b}}^{*}$ describes aerodynamic and quasi-laminar boundary-layer resistance to deposition inside the chamber, so, while ozone was used to find the value, it is applicable to all gases. For future researchers, we would suggest repeating this experiment with different flow and vegetation characteristics.

We present both measured ozone fluxes and values adjusted using this resistance analogy. While this conversion factor enables chamber flux to be scaled to ambient flux, it introduces modeling assumptions and additional uncertainty to an otherwise direct measurement.

\section{Results and discussion}

\subsection{Data processing}

We collected $\mathrm{O}_{3}$ flux data for 8 days. We used two pairs of identical tall chambers and one pair of shorter chambers. Each set of data was based on a 5-minute chamber closure, which occurred once per hour. The flux during each sampling period was assumed to be constant. Each data run was analyzed for noise and pattern, and some data sets were excluded from results.

Figure 3 is an example of a sampling period that we excluded from our results. The ozone concentration increased

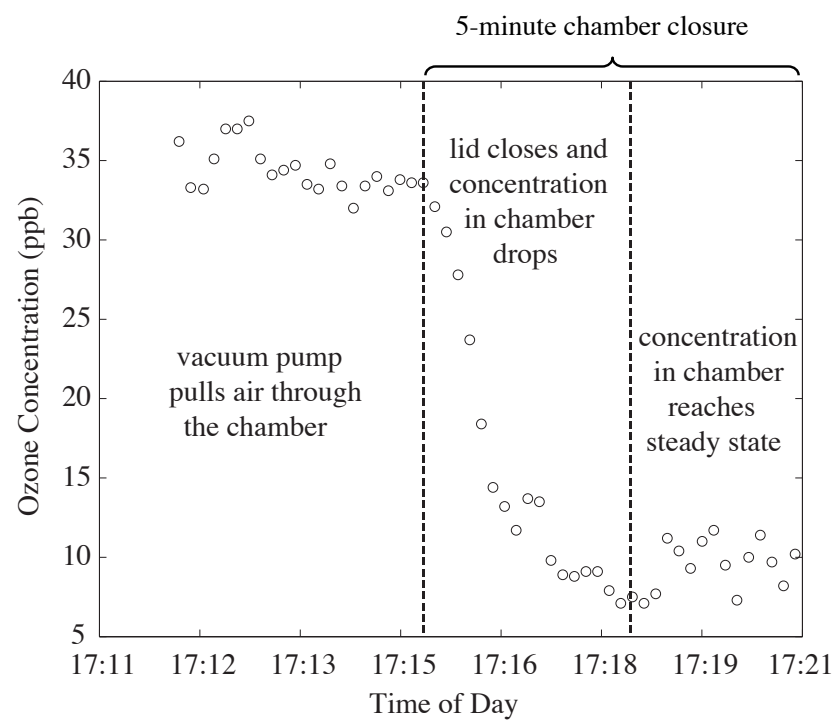

Figure 4. The plot above is an example of ozone data that can be analyzed using the steady-state mass-balance equation. The data before the lid is closed and at the end of the sample both have low noise and stay relatively constant for at least $1 \mathrm{~min}$.

by an unreasonable amount when the chamber lid opened, which likely indicates malfunction in the $2 \mathrm{~B}$ ozone monitor. Nine percent of chamber A data were excluded, $11 \%$ of chamber $\mathrm{B}$ data were excluded, and $0 \%$ of the chamber $\mathrm{C}$ data were excluded.

Figure 4 shows the ozone concentration in the chamber during one sampling period, as an example of ozone data that can be analyzed using the steady-state solution. The area before the decline of the ozone concentration represents the time period when the chamber lid was open. After the lid closed, the concentration began to decline and eventually reached a steady-state value. This data set met our dataquality requirements, as the data just before the lid closed and at the end of the sample both have low noise and stay relatively constant for at least $1 \mathrm{~min}$. Therefore, the flux was computed using the steady-state solution (Eq. 3).

In addition to the data selection mentioned above, we also looked for short-term extreme fluctuations in the ozone time series. The first step in this process was to calculate rolling 1 min averages. Next, we found the standard deviation of the six concentration values used to calculate each $1 \mathrm{~min}$ average. We excluded the $1 \mathrm{~min}$ averages with a standard deviation greater than $3 \mathrm{ppb}$. This value was chosen because, when we looked at a histogram of the standard deviations, values greater than 3 ppb were outliers. This data-quality-check process resulted in the removal of $1.4 \%$ of the $1 \mathrm{~min}$ average data.

To compute flux, we need ambient and steady-state ozone concentrations. For both of those values, we use an average over a short time window instead of a concentration at one time point to reduce uncertainty. We found the ambient 
ozone concentration for each cycle by calculating the mean of the last $2 \mathrm{~min}$ of concentration data before the chamber lid closed. We found the steady-state concentration by calculating the mean of the data between 3 and 5 min after the chamber closed. Finally, we used the ambient and steadystate concentrations we found for each data set to compute flux, using Eq. (7).

When the ambient ozone concentration is below $5 \mathrm{ppb}$, we assume that the ozone flux is zero. Ambient $\mathrm{O}_{3}$ concentrations of $5 \mathrm{ppb}$ or lower typically occur only at night, when wind speeds are low, which means that the aerodynamic resistance to deposition is high, equating to a low flux. The absolute highest flux rate that could occur, with an ambient concentration of $5 \mathrm{ppb}$, is $0.09 \mu \mathrm{g} \mathrm{m}^{-2} \mathrm{~s}^{-1}$ (from Eq. 3), and a flux rate this high is very unlikely with low wind speeds. The median ozone-flux rate measured via eddy covariance, when the ambient ozone concentration was $\leq 5 \mathrm{ppb}$, during the eight-day sampling period was $0 \mu \mathrm{g} \mathrm{m}^{-2} \mathrm{~s}^{-1}$, with a standard deviation of $0.05 \mu \mathrm{g} \mathrm{m}^{-2} \mathrm{~s}^{-1}$.

We did not use the blank chamber data to make any adjustments to the fluxes measured by the dynamic chambers. The median difference between ambient concentration and steady-state ozone concentration was $1.9 \mathrm{ppb}$ for the blank chambers. Since the uncertainty in ozone concentrations measured by the $2 \mathrm{~B}$ ozone monitor is $\pm 1.5 \mathrm{ppb}$, the concentration difference is within a $95 \%$ confidence interval for noise. Thus, correcting chamber fluxes for blank flux would only introduce more error into our measurements.

Also, the median flux measured by the blank chambers, when the open-bottom-chamber flux was nonzero, was $-0.001 \mu \mathrm{g} \mathrm{m}^{-2} \mathrm{~s}^{-1}$. This value is less than $1 \%$ of the median of the nonzero open-bottom-chamber fluxes, which was $-0.21 \mu \mathrm{g} \mathrm{m}^{-2} \mathrm{~s}^{-1}$. Therefore, correcting for the blank chamber fluxes would not have a significant impact on measurements. It was encouraging that the blank fluxes were so small, since this indicated that wall losses do not have a significant impact on the flux-chamber measurements. Since wall losses were insignificant, the chamber design could be further simplified by eliminating the blank chambers.

\subsection{Photochemistry in the chamber}

Photochemical reactions between $\mathrm{NO}, \mathrm{NO}_{2}$, and $\mathrm{O}_{3}$ can occur in the chamber and therefore must be considered in Eq. (1) (Meixner et al., 1997; Pape et al., 2009). The primary reactions of concern are

$\mathrm{NO}+\mathrm{O}_{3} \rightarrow \mathrm{NO}_{2}+\mathrm{O}_{2}$

and

$\mathrm{NO}_{2}+h v \stackrel{\mathrm{O}_{2}}{\rightarrow} \mathrm{NO}+\mathrm{O}_{3}, \lambda<420 \mathrm{~nm}$.

Pape and coworkers measured $j\left(\mathrm{NO}_{2}\right)$ inside their chamber and found that the average value of $j\left(\mathrm{NO}_{2}\right)$ inside the chamber was $48 \%$ of the value outside the chamber (Pape

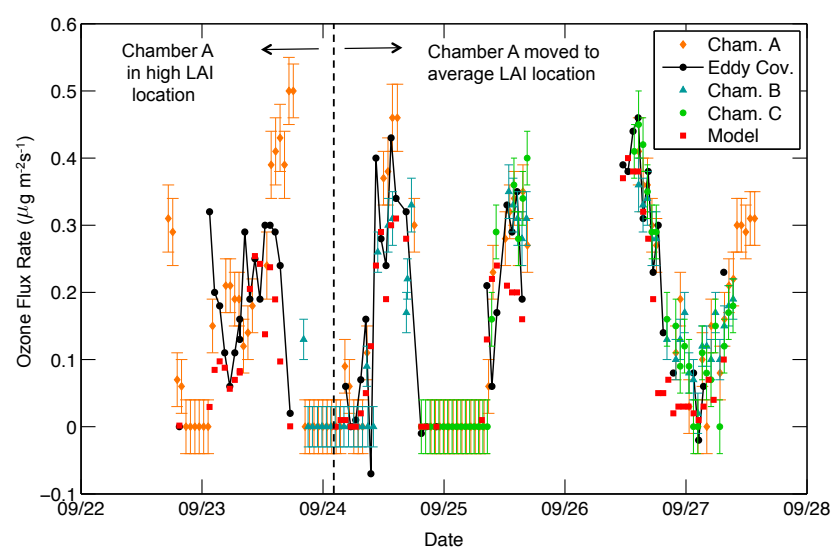

Figure 5. The plot above compares $\mathrm{O}_{3}$ fluxes measured using eddy covariance (solid black line and black dots); surface-exchange modeling (red squares); and flux chambers A (orange diamonds), B (blue triangles), and $\mathrm{C}$ (green circles). The error bars represent the $95 \%$ confidence interval. The tick marks represent midnight on the date listed.

et al., 2009). They fit a curve of $j\left(\mathrm{NO}_{2}\right)$ vs. global radiation $(G)$, and we used that curve in our calculations, since our chambers were similar in shape and material. To quantify the impact of this assumption, we calculated how increasing and decreasing $j\left(\mathrm{NO}_{2}\right)$ by $25 \%$ affects ozone flux and found that this changes ozone flux by $<1 \%$ in all cases. The maximum flux change due to photolysis in all of our results is $1.7 \%$. Thus, the impact of photolysis on ozone flux was small during our study. More information about our calculation of photolysis rate can be found in the Supplement.

\subsection{Ozone results}

We measured ozone dry deposition with flux chambers for 2 days in June, and 8 days in September. When compared with eddy-covariance measurements, flux-chamber ozone measurements were able to capture the diurnal flux trends. It is important to remember that eddy-covariance measurements are not without error. For an eddy-covariance system similar to the one used in this study, Finkelstein and Sims (2001) found that mean sampling errors for 30 min average eddycovariance $\mathrm{O}_{3}$ fluxes were in the range of $27-33 \%$.

Figure 5 shows $\mathrm{O}_{3}$ fluxes measured via eddy covariance and flux chambers $\mathrm{A}, \mathrm{B}$ and $\mathrm{C}$, and also calculated using an indirect method, which combined meteorological data and surface-exchange model for the time period between 22 and 28 September. The theory used to calculate the model values is described by Wesely (1989) and Seinfeld and Pandis (2006).

The surface-exchange model results underestimated the mean eddy-covariance flux rate by $26 \%$ between 22 and 27 September. This is a good model-to-measurement match, but it is important to remember that the models do not al- 

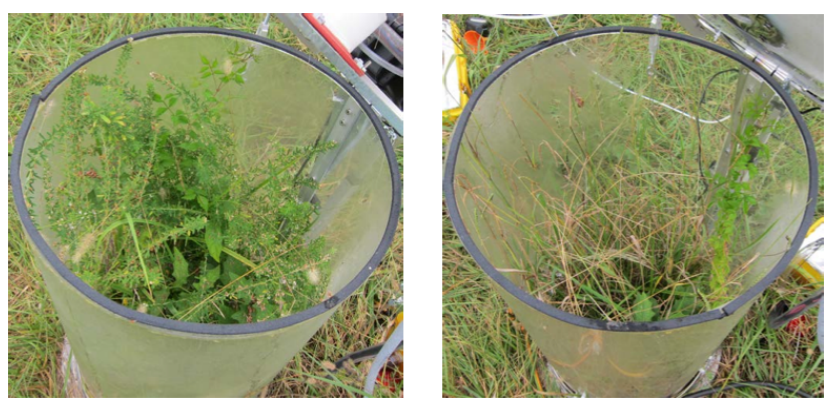

Figure 6. Chamber A (left). Chamber B (right). The vegetation in chamber A, prior to being moved on 24 September, was not representative of the typical vegetation type or LAI at the site. As a result, flux measurements prior to the move were large when compared with measurements from other chambers and eddy covariance. The vegetation in chamber $B$ was representative of the vegetation in the field.

ways predict flux accurately (Wu et al., 2012; Schwede et al., 2011).

Chamber A was moved from its original location in the field to a different position on 24 September. Prior to being moved, the chamber was on a plot of land with a lessprevalent vegetation type, which had a higher LAI than the dominant vegetation (see Fig. 6). After the chamber was moved to a location with more representative vegetation, the data matched the eddy-covariance results much better. Before the chamber was moved (18 and 23 September), the mean ozone-flux rate measured by eddy covariance was $-0.16 \mu \mathrm{g} \mathrm{m}^{-2} \mathrm{~s}^{-1}$, and the mean chamber flux rate was $-0.23 \mu \mathrm{g} \mathrm{m}^{-2} \mathrm{~s}^{-1}$, which is $48 \%$ higher than the eddy-covariance measurement. After the move (2427 September), the mean eddy-covariance flux rate was $-0.25 \mu \mathrm{g} \mathrm{m}^{-2} \mathrm{~s}^{-1}$, and the mean flux measured by the chamber was $-0.26 \mu \mathrm{g} \mathrm{m}^{-2} \mathrm{~s}^{-1}$, which is $4 \%$ higher than the eddy-covariance measurement. This difference in measurement agreement highlights the importance of selecting a chamber placement that contains vegetation representative of the footprint of the eddy-covariance tower.

Chamber B operated from 18 to 19 September, and again from 23 to 27 September. The mean ozone flux measured by the flux chamber during this period was $-0.17 \mu \mathrm{g} \mathrm{m}^{-2} \mathrm{~s}^{-1}$, which is $9 \%$ higher than the mean eddy-covariance ozone flux during the same period $\left(-0.15 \mu \mathrm{g} \mathrm{m}^{-2} \mathrm{~s}^{-1}\right)$.

Chamber $\mathrm{C}$, which is the shorter chamber, was operated between 18 and 19 September, and again between 24 and 27 September. The mean chamber flux measured during this period was $-0.115 \mu \mathrm{g} \mathrm{m}^{-2} \mathrm{~s}^{-1}$, which was $6 \%$ lower than the mean eddy-covariance flux during the same time period $\left(-0.108 \mu \mathrm{g} \mathrm{m}^{-2} \mathrm{~s}^{-1}\right)$.

In addition to the September measurements, data were collected for 4 days in June. The chambers underestimated ozone flux by $50-100 \%$ in June, and we believe that this was because the LAI was much lower in the chambers than in the field during that time. Because we did not anticipate the spatial and temporal variability in LAI, nor its subsequent impact on flux measurements, we did not measure LAI during our June sampling period. However, we estimate, by visual inspection, that LAI in the chambers was about $50 \%$ lower in June than in September. Further studies that measure ozone deposition with various known LAI values in the chamber could confirm the effects of changing LAI on measured flux. We will measure LAI in all future flux experiments.

There was not a systemic bias in the ozone flux data. The excellent agreement between the September flux-chamber and eddy-covariance measurements demonstrates that the flux chamber is capable of measuring ozone flux to grassland ecosystems when the LAI inside the chamber represents the average LAI in the field.

\subsection{Chamber versus eddy-covariance regression analysis}

Plot 7 shows a regression analysis of measured chamber flux rates and chamber flux rates that are adjusted using the chamber-to-ambient flux rate correction versus eddy covariance. While this plot is interesting, we need to be careful about placing too much emphasis on these results, since the averaging times were different for the eddy covariance (averaged over a $1 \mathrm{~h}$ period) and chamber measurements (5 min average). It is also important to remember that the eddy-covariance measurements have uncertainty, which Finklestein and Sims found to be $30 \%$, on average, for halfhourly fluxes (Finkelstein and Sims, 2001).

Linear regressions were found for the measured and corrected chamber data versus eddy-covariance data. The measured data had a slope of 0.89 and an intercept of 0.03 , with a coefficient of determination $\left(R^{2}\right)$ of 0.64 . With $95 \%$ confidence, the slope is significantly different than 1 ( $p$ value $\left.=5.8 \times 10^{-24}\right)$, and the intercept is not significantly different than $0(p$ value $=0.55)$, although it is worth noting that the intercept would be significantly different than zero at a slightly higher confidence interval.

Linear regression between the corrected chamber and eddy-covariance data yielded a slope of 0.90 and an intercept of 0.002 , with an $R^{2}$ of 0.77 . With $95 \%$ confidence, the slope is significantly different than 1 ( $p$ value $\left.=51.3 \times 10^{-33}\right)$, and the intercept is not significantly different than zero ( $p$ value $=0.89$ ). While the corrected data has a slope closer to 1 and an intercept closer to 0 than the measured data, the two lines are not significantly different in slope $(p$ value $=0.92)$ or intercept $(p$ value $=0.91)$. Perhaps a more important result of the correction is that it pulled the 2 most extreme chamber flux values (both $-0.5 \mu \mathrm{g} \mathrm{m}^{-2} \mathrm{~s}^{-1}$ ), closer to agreement with the eddy-covariance values; this is reflected in the increased value of $R^{2}$.

The mean flux rate for the data in Fig. 7 is $-0.19 \mu \mathrm{g} \mathrm{m}^{-2} \mathrm{~s}^{-1}$ for eddy covariance, $-0.20 \mu \mathrm{g} \mathrm{m}^{-2} \mathrm{~s}^{-1}$ for the measured chamber data, and $-0.17 \mu \mathrm{g} \mathrm{m}^{-2} \mathrm{~s}^{-1}$ for 


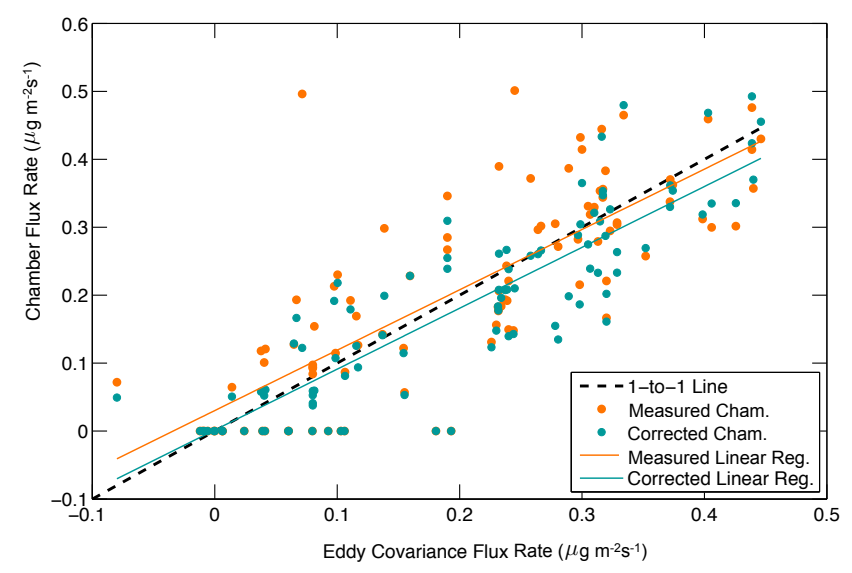

Figure 7. The plot above is a comparison of ozone fluxes measured using flux chambers with fluxes obtained via eddy covariance. The orange dots represent fluxes measured by the chambers, and the blue dots represent chamber fluxes that have been corrected using the adjusted resistance analogy. The dashed line is a 1-to-1 line. The orange line represents a linear regression of the measured chamber fluxes, and the blue line is a linear regression of the corrected chamber fluxes.

the corrected chamber data. While the mean of the corrected chamber flux rate is $9 \%$ farther from the eddy covariance than the measured chamber flux rate, both are well within the uncertainty of the eddy-covariance measurements. Based on the reduction of extreme values and increased $R^{2}$, we believe that performing the correction improves the chamber results overall.

\subsection{Seasonal flux and implications for chamber flux measurements}

We completed this validation work in September, which demonstrates chamber performance in the late summer/early fall. In order to predict chamber performance in other seasons, we used seasonal meteorological data from the Duke Forest to calculate typical values of $r_{\mathrm{a}}, r_{\mathrm{b}}$, and $r_{\mathrm{c}}$ as well as the chamber-to-ambient flux correction factors $\left(F_{\mathrm{cham}} / F_{\mathrm{amb}}\right)$ for winter, spring, summer, and fall. The meteorological data set includes air temperature, wind speed, friction velocity, relative humidity, global radiation, and rainfall information from 2013. We chose 1 week of representative data for each season (6-12 February, 21-27 April, 2-8 August, 2-8 November). We used a surface-exchange model, combined with the meteorological data, to calculate $r_{\mathrm{a}}, r_{\mathrm{b}}$, and $r_{\mathrm{c}}$. The model is based on the theory in Wesely (1989) and Seinfeld and Pandis (2006). A constant value of $57.5 \mathrm{~s} \mathrm{~m}^{-1}$ was used for $r_{\text {purge }}+r_{\mathrm{b}}^{*}$ (see Sect. 2.7 for details on the calculation of $r_{\text {purge }}+r_{\mathrm{b}}^{*}$ ).

As shown in Table 3, the aerodynamic $\left(r_{\mathrm{a}}\right)$ and quasilaminar boundary-layer $\left(r_{\mathrm{b}}\right)$ resistances are similar in all seasons. The overall median canopy resistance is lowest in the summer $\left(110 \mathrm{~s} \mathrm{~m}^{-1}\right)$, slightly higher in the spring $\left(147 \mathrm{~s} \mathrm{~m}^{-1}\right)$, higher still in the fall $\left(263 \mathrm{~s} \mathrm{~m}^{-1}\right)$, and drastically higher in the winter $\left(1348 \mathrm{~s} \mathrm{~m}^{-1}\right)$. In the spring, summer, and fall, the canopy resistance makes up approximately $50 \%$ of the total resistance to deposition, whereas in the winter it contributes $90 \%$ of the total deposition resistance. This discrepancy in canopy resistance results in seasonal variability of the chamber-to-ambient flux correction factors. The range of correction factors (5th to 95th percentile) is much larger in the spring (0.86-2.89), summer (0.87-2.82), and fall $(0.92-2.84)$ than in the winter $(0.99-1.35)$.

At night, the correction factor is typically greater than 1 , which has the effect of reducing the flux measured by the chamber. This accounts for the fact that the turbulence in the chamber may exceed the ambient turbulence at night. The magnitude of the nighttime correction factor is reduced in the winter as a result of the very large canopy resistance, which is so dominant that differences in aerodynamic conditions are inconsequential. During the day, the typical correction factor is close to 1 in all seasons, and sometimes below 1, which means that the turbulence in the chamber during the day typically matches the ambient conditions well but can be lower or higher than ambient at any given time.

Our validation experiments were conducted in late summer/early fall. Since the chamber-to-ambient correction factors vary the most in the spring, summer, and fall, we have demonstrated that chambers can accurately predict flux when the turbulence in the chambers differs from ambient. Due to the dominance of canopy resistance in the winter, aerodynamic differences should be negligible at that time of year. In addition to correction factors, it is important to consider overall median deposition velocities, which are greatest in the spring and summer $\left(-0.35\right.$ and $\left.-0.32 \mathrm{~cm} \mathrm{~s}^{-1}\right)$, slightly lower in the fall $\left(-0.27 \mathrm{~cm} \mathrm{~s}^{-1}\right)$, and very low in the winter $\left(-0.07 \mathrm{~cm} \mathrm{~s}^{-1}\right)$. Since ozone concentrations are typically higher in warm weather, fluxes are largest in the summer and spring, slightly lower in the fall, and lowest in the winter. Chamber uncertainty, as a percentage of a single flux measurement, varies from 10 to $65 \%$ and is highest when fluxes are low. Thus, while meteorology should not impact the accuracy of chamber measurements in different seasons, uncertainty as a percentage of flux will be higher in the winter than in other seasons. It is important to remember that eddycovariance measurements also have a higher uncertainty as a percentage of flux in the wintertime, so the method is not as strong of a benchmark as it is in the summer. In summary, we anticipate that a comparison between fluxes measured with the dynamic flux chambers and with the eddy-covariance method would yield similar agreement in all seasons except winter. In winter, both measurement methods have higher uncertainty, so a comparison might yield noisier results. 
Table 3. Seasonal mean resistance, correction factor, and deposition Velocity.

\begin{tabular}{|c|c|c|c|c|c|}
\hline & & Winter & Spring & Summer & Fall \\
\hline \multirow{7}{*}{ Overall } & median $v_{\mathrm{d}}\left(\mathrm{cm} \mathrm{s}^{-1}\right)$ & 0.07 & 0.35 & 0.32 & 0.27 \\
\hline & median $r_{\mathrm{a}}\left(\mathrm{s} \mathrm{m}^{-1}\right)$ & 56 & 45 & 71 & 67 \\
\hline & median $r_{\mathrm{b}}\left(\mathrm{s} \mathrm{m}^{-1}\right)$ & 21 & 20 & 38 & 30 \\
\hline & median $r_{\mathrm{c}}\left(\mathrm{s} \mathrm{m}^{-1}\right)$ & 1348 & 147 & 110 & 263 \\
\hline & median $F_{\text {cham }} / F_{\text {amb }}$ & $1.01 \pm 0.02$ & $1.02 \pm 0.9$ & $1.20 \pm 0.74$ & $1.12 \pm 1.0$ \\
\hline & 95th percentile $F_{\text {cham }} / F_{\text {amb }}$ & 1.35 & 2.89 & 2.82 & 2.84 \\
\hline & 5th percentile $F_{\text {cham }} / F_{\mathrm{amb}}$ & 0.99 & 0.86 & 0.87 & 0.92 \\
\hline \multirow{7}{*}{ Daytime } & median $v_{\mathrm{d}}\left(\mathrm{cm} \mathrm{s}^{-1}\right)$ & 0.11 & 0.56 & 0.63 & 0.38 \\
\hline & median $r_{\mathrm{a}}\left(\mathrm{s} \mathrm{m}^{-1}\right)$ & 39 & 30 & 35 & 33 \\
\hline & median $r_{\mathrm{b}}\left(\mathrm{s} \mathrm{m}^{-1}\right)$ & 15 & 13 & 21 & 16 \\
\hline & median $r_{\mathrm{c}}\left(\mathrm{s} \mathrm{m}^{-1}\right)$ & 876 & 130 & 103 & 209 \\
\hline & median $F_{\text {cham }} / F_{\text {amb }}$ & $1.00 \pm 0.02$ & $0.94 \pm 0.31$ & $0.99 \pm 0.53$ & $0.97 \pm 0.66$ \\
\hline & 95th percentile $F_{\text {cham }} / F_{\text {amb }}$ & 1.03 & 1.53 & 1.47 & 1.25 \\
\hline & 5th percentile $F_{\text {cham }} / F_{\mathrm{amb}}$ & 0.98 & 0.84 & 0.84 & 0.91 \\
\hline \multirow{7}{*}{ Nighttime } & median $v_{\mathrm{d}}\left(\mathrm{cm} \mathrm{s}^{-1}\right)$ & 0.05 & 0.25 & 0.23 & 0.22 \\
\hline & median $r_{\mathrm{a}}\left(\mathrm{s} \mathrm{m}^{-1}\right)$ & 91 & 101 & 145 & 128 \\
\hline & median $r_{\mathrm{b}}\left(\mathrm{s} \mathrm{m}^{-1}\right)$ & 32 & 44 & 77 & 56 \\
\hline & median $r_{\mathrm{c}}\left(\mathrm{s} \mathrm{m}^{-1}\right)$ & 1348 & 245 & 255 & 282 \\
\hline & median $F_{\text {cham }} / F_{\mathrm{amb}}$ & $1.04 \pm 0.04$ & $1.31 \pm 1.14$ & $1.57 \pm 0.74$ & $1.38 \pm 1.1$ \\
\hline & 95th percentile $F_{\text {cham }} / F_{\mathrm{amb}}$ & 1.44 & 3.65 & 3.24 & 3.1 \\
\hline & 5th percentile $F_{\text {cham }} / F_{\mathrm{amb}}$ & 1.0 & 0.97 & 1.06 & 1.0 \\
\hline
\end{tabular}

\section{Conclusions}

Ozone deposition onto a grassland ecosystem was measured using dynamic flux chambers and eddy covariance. Ozonedeposition measurements from the two methods matched very well (4-10\% difference) when the LAI inside the chambers was representative of the average LAI in the field. This discrepancy is within the uncertainty of eddy covariance, and the flux chambers are considered an accurate measurement system under these conditions. There was not a bias in the chamber data, when compared with the eddy-covariance data.

When LAI inside the chambers was significantly higher or lower than the rest of the field, chamber measurements over- or underpredicted flux, respectively. A discrepancy between chamber and average LAI values can be caused by both inconsistency in vegetation density and differences in vegetation species. Eddy-covariance systems can only measure net flux to an entire fetch $\left(>100 \mathrm{~m}^{2}\right)$, which means that they measure a mean flux to all vegetation in the field and cannot measure flux to small patches of different vegetation types. Flux chambers are able to measure flux onto different patches of vegetation, which enables the user to understand the relative contribution of different vegetation species to total flux.

In this work, our strategy was to place every chamber on a plot of vegetation that represented the average vegetation in the field. This enabled us to confirm that the results were consistent between chambers. In the field at the Duke Forest, the minority vegetation types represent such a small fraction of the overall grassland that it is very unlikely they have a large net effect on the flux.

It would be very interesting, in future work, to intentionally place the chambers over different types of vegetation in a field and attempt to quantify what percentage of the vegetation each plot represents, and then use a weighted average of ozone fluxes onto the five types of vegetation to estimate the overall flux.

We found that the median ozone flux measured by the blank chambers, when the open-bottom-chamber flux was nonzero, was $-0.001 \mu \mathrm{g} \mathrm{m}^{-2} \mathrm{~s}^{-1}$. This value is less than $1 \%$ of the median of the nonzero open-bottom-chamber fluxes, which was $-0.21 \mu \mathrm{g} \mathrm{m}^{-2} \mathrm{~s}^{-1}$. Therefore, we can conclude that we achieved the design goal of minimizing trace-gas interactions with the walls of the chamber.

$\mathrm{CO}_{2}$ measurements were conducted for one $20 \mathrm{~h}$ period, and the flux chamber captured the diurnal trend in $\mathrm{CO}_{2}$ flux. The quantity of the data was not sufficient to validate chamber performance, but the results show promise, and additional experiments will be conducted to confirm that the flux chambers can measure $\mathrm{CO}_{2}$ deposition accurately.

Flux-chamber $\mathrm{NO}_{\mathrm{x}}$ measurements were conducted for 4 days. Unfortunately, the eddy-covariance system for measuring $\mathrm{NO}_{\mathrm{x}}$ was not available during this field campaign, so comparisons could not be made. However, $\mathrm{NO}_{\mathrm{x}}$ fluxes measured by the dynamic chambers did fall in the expected range 
for the site. Additional experiments will be performed to confirm that the chamber $\mathrm{NO}_{\mathrm{x}}$-flux measurements are accurate.

The ultimate goal of our research is to operate the chambers with inexpensive sensors, and the next phase of the project is to validate performance for these sensors. Future work will also consist of measuring different species and using the chambers to measure spatial variability in dry deposition.

\section{The Supplement related to this article is available online at doi:10.5194/amt-8-267-2015-supplement.}

Acknowledgements. We are grateful for the opportunity to do this work, which was funded by the Electric Power Research Institute (EPRI). We would like to thank Corey Miller for his help building the flux chambers. We would like to thank Peter Hamlington, Nick Clements, Bill Mitchell, and Andrew Turnipseed for helpful discussions. This project would not have been possible without equipment borrowed from Christine Wiedinmyer and John Ortega, at the National Center for Atmospheric Research, as well as Joanna Gordon and Ashley Collier. Ricardo Piedrahita and Nick Masson's sensor work is the basis for the inexpensive sensor portion of this project.

Disclaimer. This document has been reviewed in accordance with US Environmental Protection Agency policy and approved for publication. The views expressed in this article are those of the author[s] and do not necessarily represent the views or policies of the US Environmental Protection Agency.

Edited by: T. F. Hanisco

\section{References}

Aeschlimann, U., Nösberger, J., Edwards, P. J., Schneider, M. K., Richter, M., and Blum, H.: Responses of net ecosystem $\mathrm{CO}_{2}$ exchange in managed grassland to long-term $\mathrm{CO}_{2}$ enrichment, $\mathrm{N}$ fertilization and plant species, Plant Cell Environ., 28, 823-833, 2005.

Altimir, N., Vesala, T., Keronen, P., Kulmala, M., and Hari, P.: Methodology for direct field measurements of ozone flux to foliage with shoot chambers, Atmos. Environ., 36, 19-29, 2002.

Baldocchi, D. D., Hincks, B. B., and Meyers, T. P.: Measuring biosphere-atmosphere exchanges of biologically related gases with micrometeorological methods, Ecology, 69, 1331-1340, 1988.

Benedict, K. B., Day, D., Schwandner, F. M., Kreidenweis, S. M., Schichtel, B., Malm, W. C., and Collett Jr., J. L.: Observations of atmospheric reactive nitrogen species in Rocky Mountain National Park and across northern Colorado, Atmos. Environ., 64, 66-76, 2013.

Breuninger, C., Oswald, R., Kesselmeier, J., and Meixner, F. X.: The dynamic chamber method: trace gas exchange fluxes ( $\mathrm{NO}, \mathrm{NO}_{2}$, $\mathrm{O}_{3}$ ) between plants and the atmosphere in the laboratory and in the field, Atmos. Meas. Tech., 5, 955-989, doi:10.5194/amt-5955-2012, 2012.
Breuninger, C., Meixner, F. X., and Kesselmeier, J.: Field investigations of nitrogen dioxide $\left(\mathrm{NO}_{2}\right)$ exchange between plants and the atmosphere, Atmos. Chem. Phys., 13, 773-790, doi:10.5194/acp-13-773-2013, 2013.

Brook, J. R., Zhang, L., Di-Giovanni, F., and Padro, J.: Description and evaluation of a model of deposition velocities for routine estimates of air pollutant dry deposition over North America: Part I: model development, Atmos. Environ., 33, 5037-5051, 1999.

Chamberlain, A. and Chadwick, R. C.: Deposition of airborne radioiodine vapour, Nucleonics, 11, 22-25, 1953.

DeHayes, D. H., Schaberg, P. G., Hawley, G. J., and Strimbeck, G. R.: Acid rain impacts on calcium nutrition and forest health alteration of membrane-associated calcium leads to membrane destabilization and foliar injury in red spruce, BioScience, 49, 789-800, 1999.

Driscoll, C. T., Lawrence, G. B., Bulger, A. J., Butler, T. J., Cronan, C. S., Eagar, C., Lambert, K. F., Likens, G. E., Stoddard, J. L., and Weathers, K.: Acidic Deposition in the Northeastern United States: Sources and Inputs, Ecosystem Effects, and Management Strategies: The effects of acidic deposition in the northeastern United States include the acidification of soil and water, which stresses terrestrial and aquatic biota, BioScience, 51, 180-19, 2001.

EPA US: Clean Air Status and Trends Network 2010 Annual Report, Tech. rep., AMEC Environment \& Infrastructure, Inc, prepared for US EPA Under Contract No. EP-W-09-028, 2010.

Fangmeier, A., Hadwiger-Fangmeier, A., Van der Eerden, L., and Jäger, H.-J.: Effects of atmospheric ammonia on vegetation - a review, Environ. Pollut., 86, 43-82, 1994.

Fenn, M. E., Poth, M. A., Aber, J. D., Baron, J. S., Bormann, B. T., Johnson, D. W., Lemly, A. D., McNulty, S. G., Ryan, D. F., and Stottlemyer, R.: Nitrogen excess in North American ecosystems: predisposing factors, ecosystem responses, and management strategies, Ecol. Appl., 8, 706-733, 1998.

Finkelstein, P. and Sims, P.: Sampling error in eddy correlation flux measurements, J. Geophys. Res., 106, 3503-3509, 2001.

Flechard, C. R., Nemitz, E., Smith, R. I., Fowler, D., Vermeulen, A. T., Bleeker, A., Erisman, J. W., Simpson, D., Zhang, L., Tang, Y. S., and Sutton, M. A.: Dry deposition of reactive nitrogen to European ecosystems: a comparison of inferential models across the NitroEurope network, Atmos. Chem. Phys., 11, 2703-2728, doi:10.5194/acp-11-2703-2011, 2011.

Fluxnet: Duke Forest Open Field, available at: http://fluxnet.ornl. gov/site/867 (last access: 14 December 2013), 2013.

Foken, T. and Wichura, B.: Tools for the quality assessment of surface-based flux measurements, Agr. Forest Meteorol., 78, 83$105,1996$.

Galbally, I. E. and Roy, C. R.: Destruction of ozone at the earth's surface, Q. J. Roy. Meteor. Soc., 106, 599-620, 1980.

Geßler, A., Rienks, M., and Rennenberg, $\mathrm{H} .: \mathrm{NH}_{3}$ and $\mathrm{NO}_{2}$ fluxes between beech trees and the atmosphere-correlation with climatic and physiological parameters, New Phytol., 147, 539-560, 2000.

Gillis, A. and Miller, D. R.: Some potential errors in the measurement of mercury gas exchange at the soil surface using a dynamic flux chamber, Sci. Total Environ., 260, 181-189, 2000.

Guesten, H., Heinrich, G., Schmidt, R., and Schurath, U.: Tools for the quality assessment of surface-based flux measurements, J. Atmos. Chem., 14, 73-84, 1992. 
Gut, A., Van Dijk, S., Scheibe, M., Rummel, U., Welling, M., Ammann, C., Meixner, F., Kirkman, G., Andreae, M., and Lehmann, B.: NO emission from an Amazonian rain forest soil: continuous measurements of NO flux and soil concentration, J. Geophys. Res.-Atmos., 107, LBA 24-1-LBA 24-10, doi:10.1029/2001JD000521, 2002.

Horst, T.: A simple formula for attenuation of eddy fluxes measured with first-order-response scalar sensors, Bound.-Lay. Meteorol., 82, 219-233, 1997.

Horst, T. and Weil, J.: How far is far enough? The fetch requirements for micrometeorological measurement of surface fluxes, J. Atmos. Ocean. Tech., 11, 1018-1025, 1994.

Horváth, L., Führer, E., and Lajtha, K.: Nitric oxide and nitrous oxide emission from Hungarian forest soils; linked with atmospheric N-deposition, Atmos. Environ., 40, 7786-7795, 2006.

Kaimal, J. and Finnigan, J.: Atmospheric Boundary-Layer Flows: Their Structure and Measurement, Oxford University Press, 1994.

Kirkman, G., Gut, A., Ammann, C., Gatti, L., Cordova, A., Moura, M., Andreae, M., and Meixner, F.: Surface exchange of nitric oxide, nitrogen dioxide, and ozone at a cattle pasture in Rondonia, Brazil, J. Geophys. Res.-Atmos., 107, LBA 51-1LBA 51-17, doi:10.1029/2001JD000523, 2002.

Kitzler, B., Zechmeister-Boltenstern, S., Holtermann, C., Skiba, U., and Butterbach-Bahl, K.: Nitrogen oxides emission from two beech forests subjected to different nitrogen loads, Biogeosciences, 3, 293-310, doi:10.5194/bg-3-293-2006, 2006.

Li, Y., Aneja, V. P., Arya, S., Rickman, J., Brittig, J., Roelle, P., and Kim, D.: Nitric oxide emission from intensively managed agricultural soil in North Carolina, J. Geophys. Res.-Atmos., 104, 26115-26123, 1999.

Masson, N.: UPOD: An open-source platform for air quality monitoring, available at: http://mobilesensingtechnology.com/ (last access: 10 January 2014), 2014.

Meixner, F., Fickinger, T., Marufu, L., Serca, D., Nathaus, F., Makina, E., Mukurumbira, L., and Andreae, M.: Preliminary results on nitric oxide emission from a southern African savanna ecosystem, Nutr. Cycl. Agroecosys., 48, 123-138, 1997.

Muller, J. B. A., Percival, C. J., Gallagher, M. W., Fowler, D., Coyle, M., and Nemitz, E.: Sources of uncertainty in eddy covariance ozone flux measurements made by dry chemiluminescence fast response analysers, Atmos. Meas. Tech., 3, 163-176, doi:10.5194/amt-3-163-2010, 2010.

Musselman, R. C., Lefohn, A. S., Massman, W. J., and Heath, R. L.: A critical review and analysis of the use of exposure and fluxbased ozone indices for predicting vegetation effects, Atmos. Environ., 40, 1869-1888, 2006.

Norman, J., Kucharik, C., Gower, S., Baldocchi, D., Crill, P., Rayment, M., Savage, K., and Striegl, R.: A comparison of six methods for measuring soil-surface carbon dioxide fluxes, J. Geophys. Res.-Atmos., 102, 28771-28777, 1997.

Pape, L., Ammann, C., Nyfeler-Brunner, A., Spirig, C., Hens, K., and Meixner, F. X.: An automated dynamic chamber system for surface exchange measurement of non-reactive and reactive trace gases of grassland ecosystems, Biogeosciences, 6, 405429, doi:10.5194/bg-6-405-2009, 2009.

Parrish, D. D., Williams, E. J., Fahey, D. W., Liu, S. C., and Fehsenfeld, F. C.: Measurement of nitrogen oxide fluxes from soils:
Intercomparison of enclosure and gradient measurement techniques, J. Geophys. Res.-Atmos., 92, 2165-2171, 1987.

Pleim, J. E., Bash, J. O., Walker, J. T., and Cooter, E. J.: Development and evaluation of an ammonia bidirectional flux parameterization for air quality models, J. Geophys. Res.-Atmos., 118, 3794-3806, 2013.

Pilegaard, K.: Air-soil exchange of $\mathrm{NO}, \mathrm{NO}_{2}$ and $\mathrm{O}_{3}$ in forests, Water Air Soil Pollut. Focus, 1, 79-88, 2001.

Remde, A., Ludwig, J., Meixner, F. X., and Conrad, R.: A study to explain the emission of nitric oxide from a marsh soil, J. Atmos. Chem., 17, 249-275, 1993.

SAS Institute: Version 9.3 System Help, 2003.

Saylor, R. D., Wolfe, G. M., Meyers, T. P., and Hicks, B. B.: A corrected formulation of the Multilayer Model (MLM) for inferring gaseous dry deposition to vegetated surfaces, Atmos. Environ., 92, 141-145, 2014.

Schwede, D. B., Zhang, L., Vet, R., and Lear, G.: An intercomparison of the deposition models used in the CASTNET and CAPMoN networks, Atmos. Environ., 45, 1337-1346, 2011.

Seinfeld, J. H. and Pandis, S. N.: Atmospheric Chemistry and Physics, 2nd Edn., Wiley, 2006.

Sparks, J. P., Monson, R. K., Sparks, K. L., and Lerdau, M.: Leaf uptake of nitrogen dioxide $\left(\mathrm{NO}_{2}\right)$ in a tropical wet forest: implications for tropospheric chemistry, Oecologia, 127, 214-221, 2001.

Stella, P., Loubet, B., Laville, P., Lamaud, E., Cazaunau, M., Laufs, S., Bernard, F., Grosselin, B., Mascher, N., Kurtenbach, R., Mellouki, A., Kleffmann, J., and Cellier, P.: Comparison of methods for the determination of $\mathrm{NO}-\mathrm{O}_{3}-\mathrm{NO}_{2}$ fluxes and chemical interactions over a bare soil, Atmos. Meas. Tech., 5, 1241-1257, doi:10.5194/amt-5-1241-2012, 2012.

Turnipseed, A., Burns, S., Moore, D., Hu, J., Guenther, A., and Monson, R.: Controls over ozone deposition to a high elevation subalpine forest, Agr. Forest Meteorol., 149, 1447-1459, 2009.

Unsworth, M., Heagle, A., and Heck, W.: Gas exchange in open-top field chambers - I. Measurement and analysis of atmospheric resistances to gas exchange, Atmos. Environ., 18, 373-380, 1984.

Webb, E. K., Pearman, G. I., and Leuning, R.: Correction of flux measurements for density effects due to heat and water vapour transfer, Q. J. Roy. Meteor. Soc., 106, 85-100, 1980.

Wesely, M.: Parameterization of surface resistances to gaseous dry deposition in regional-scale numerical models, Atmos. Environ., 23, 1293-1304, 1989.

Wesely, M. and Hicks, B. B.: A review of the current status of knowledge on dry deposition, Atmos. Environ., 34, 2261-2282, 2000.

Williams, E. and Davidson, E.: An intercomparison of two chamber methods for the determination of emission of nitric oxide from soil, Atmos. Environ. A-Gen., 27, 2107-2113, 1993.

Williams, M. and Tonnessen, K.: Critical loads for inorganic nitrogen deposition in the Colorado Front Range, USA, Ecol. Appl., 10, 1648-1665, 2000.

Wu, W., Zhang, G., and Kai, P.: Ammonia and methane emissions from two naturally ventilated dairy cattle buildings and the influence of climatic factors on ammonia emissions, Atmos. Environ., 61, 232-243, 2012.

Wu, Z., Wang, X., Chen, F., Turnipseed, A. A., Guenther, A. B., Niyogi, D., Charusombat, U., Xia, B., William Munger, J., and Alapaty, K.: Evaluating the calculated dry deposition veloci- 
ties of reactive nitrogen oxides and ozone from two community models over a temperate deciduous forest, Atmos. Environ., 45, 2663-2674, 2011.

Zahn, A., Weppner, J., Widmann, H., Schlote-Holubek, K., Burger, B., Kühner, T., and Franke, H.: A fast and precise chemiluminescence ozone detector for eddy flux and airborne application, Atmos. Meas. Tech., 5, 363-375, doi:10.5194/amt-5-3632012, 2012.
Zhang, L., Brook, J. R., and Vet, R.: A revised parameterization for gaseous dry deposition in air-quality models, Atmos. Chem. Phys., 3, 2067-2082, doi:10.5194/acp-3-2067-2003, 2003. 